University of Montana

ScholarWorks at University of Montana

\title{
Stress and Developmental Stability: Vegetation Removal Causes Increased Fluctuating Asymmetry in Shrews
}

\author{
Alexander V. Badyaev \\ Kerry R. Foresman \\ University of Montana - Missoula, foresman@mso.umt.edu \\ Miguel V. Fernandes
}

Follow this and additional works at: https://scholarworks.umt.edu/biosci_pubs

Part of the Biology Commons

Let us know how access to this document benefits you.

\section{Recommended Citation}

Badyaev, Alexander V.; Foresman, Kerry R.; and Fernandes, Miguel V., "Stress and Developmental Stability: Vegetation Removal Causes Increased Fluctuating Asymmetry in Shrews" (2000). Biological Sciences Faculty Publications. 253.

https://scholarworks.umt.edu/biosci_pubs/253

This Article is brought to you for free and open access by the Biological Sciences at ScholarWorks at University of Montana. It has been accepted for inclusion in Biological Sciences Faculty Publications by an authorized administrator of ScholarWorks at University of Montana. For more information, please contact scholarworks@mso.umt.edu. 


\title{
STRESS AND DEVELOPMENTAL STABILITY: VEGETATION REMOVAL CAUSES INCREASED FLUCTUATING ASYMMETRY IN SHREWS
}

\author{
Alexander V. Badyaev,' Kerry R. Foresman, and Miguel V. Fernandes \\ Division of Biological Sciences, University of Montana, Missoula, Montana 59812-1002 USA
}

\begin{abstract}
Environmental stress can increase phenotypic variation in populations by affecting developmental stability of individuals. While such increase in variation results from individual differences in ability to buffer stress, groups of individuals and different traits may have different sensitivity to stressful conditions. For example, the sex that is under stronger directional selection for faster growth may be more sensitive to stressful conditions during development. On an individual level, stress-induced variation in a trait may be related to the strength of stabilizing selection that acts on the trait. We experimentally examined sensitivity of mandibular development to stress in a free-living population of common shrews (Sorex cinereus), a short-lived insectivore mammal with very limited dispersal and nearly continuous foraging activity. We found a strong increase in asymmetry in shrews born under stressful conditions. Increased asymmetry was associated with lower physiological condition in both control and stressed populations, although the effect of asymmetry on fitness was more pronounced under stressful conditions. Males' developmental stability was more sensitive to stressful conditions than developmental stability of females, suggesting that their apparently faster and more variable growth is more sensitive to stress than is growth of females. Mandible traits differed in their sensitivity to environmental changes. Preliminary results suggest that this differential sensitivity is proportional to the degree of developmental and functional morphological integration among mandibular traits.
\end{abstract}

Key words: asymmetry; developmental stability; environmental stress; lower mandible; Sorex cinereus.

\section{INTRODUCTION}

Environmental stress can increase phenotypic variation in populations by affecting developmental stability of individuals (e.g., Selyé 1956, Hoffmann and Parsons 1991, Graham et al. 1993, Kieser 1993). Individual inability to undergo normal development under stressful conditions often is expressed as either increased asymmetry in bilateral traits (Van Valen 1962, Palmer and Strobeck 1986, Møller and Swaddle 1997) or increase in frequency of phenotypic deviants (Rasmuson 1960). While increased developmental instability may be proximately caused by external environment, the extent to which different traits respond to the environmental cues can have a genetic basis (e.g., Siegel and Doyle 1975a). Differential sensitivities of development to stress can evolve under natural selection (Reeve 1960, Via 1994) that may favor increased instability under stressful conditions (Schmalhausen 1949, Bradshaw 1965, Bull 1987, Holloway et al. 1997, Simmons and Johnston 1997).

The evolutionary importance of environmentally in-

Manuscript received 25 June 1998; revised 11 December 1998: accepted 23 December 1998; final version received 20 January 1999.

'Present address: Department of Biological Sciences, Auburn University, Auburn, Alabama 36849-5414 USA.

E-mail: abadyaev@selway.umt.edu duced variation in traits developmental stability is not well understood (Simmons and Johnson 1997). The primary reason for this is that studies of free-living populations documenting effects of distinct environmental change (e.g., Ames et al. 1979, Jagoe and Haines 1985, Møller 1993), especially over several generations (Clarke and McKenzie 1992), are rare and most of our knowledge about variation in developmental stability following stress is derived from laboratory research (e.g., Siegel and Smookler 1973, Siegel and Doyle, 1975a, b, Sciulli et al. 1979, Siegel et al. 1992).

Studies of association between developmental stability and environmental changes in natural populations are important for several reasons. First, laboratory studies often use animals under abnormally low initial stress conditions (e.g., competition and predation are largely eliminated). As a result, responses of these animals to the extreme, experimentally induced stress may be of limited value to studies that explore adaptiveness and sensitivity of traits to natural ranges of stresses (Parsons 1990). On the contrary, well-designed experiments with free-living populations that are subject to an array of natural stresses coincident with the environmental change of interest could provide insight into the natural range of reaction to stress and the role variation in individual quality may play in this response (Parsons 1993). Second, with this information, comparisons of experimental stresses to the range of natural 
fluctuations in the environment of free-living populations become possible, and thus further our understanding of the evolution of stress resistance (e.g., Shandorff 1997). Additionally, such comparisons allow us to examine natural and sexual selection on traits that reliably indicate stress resistance (Møller and Pomiankowski 1993, Manning and Chamberlain, 1994), and the role periodic stressful events may play in forming preferences for the ability to buffer such stresses (e.g., Badyaev 1998). Finally, indices of developmental stability are frequently used to evaluate effects of pollution, inbreeding, and changes in habitat suitability for freeliving populations (Valentine and Soulé 1973, Harris and Nweeia 1980, Wayne et al. 1986, Zakharov and Yablokov 1989, Picton et al. 1992, Badyaev et al. 1998), and studies of developmental stability in natural populations provide us with tools to monitor changes in the range and degree of stresses affecting populations (Leary and Allendorf 1989, Bailit et al. 1970, Møller and Swaddle 1997).

In this study we examined effects of logging on developmental stability in free-living populations of common shrew, Sorex cinereus. In forested landscapes, logging practices drastically alter the vegetation structure of the overstory and understory canopy. Such loss of vegetation often increases solar radiation and wind in the understory, and creates entirely different microclimates from that of unlogged forest (e.g., Chen et al. 1993). Pronounced changes in microclimate and vegetation structure strongly affect food resources and foraging efficiency of small mammals (e.g., Geier and Best 1980, Churchfield 1982), ultimately influencing the physiological condition of individuals and especially the condition of pregnant females (e.g., McShea and Maddison 1989, Zakharov et al. 1991). Common shrews are especially suitable for studies of environmental variation in developmental stability. Shrews are short-lived $(18 \mathrm{mo})$ insectivore mammals with a majority of breeding occurring in a short period of time (Foresman and Long 1998). Shrews have a very short period of skeletal growth $(6 \mathrm{~d}$ prenatal and $20 \mathrm{~d}$ postnatal growth; Foresman 1994) and nearly continuous prey-searching and foraging activity (Genoud 1988). Studies in Eurasia showed that shrew skeletal growth is highly sensitive to variation in environmental conditions (e.g., Pankakoski et al. 1992). In addition, shrews have limited dispersal (e.g., Stockley et al. 1994), thus making it possible to design a field study that would account for possible immigration and emigration.

Here we examine changes in developmental stability in common shrews as a result of changes in vegetation structure. We specifically examine the hypothesis that if pregnant females inhabiting the vegetation removal (VR) areas experience more energetically costly foraging, lower food quality, or greater physiological expenditures as a result of microclimate change, we should see increases in developmental instability in their offspring compared with offspring of females that underwent pregnancy under control conditions. To examine whether variation in developmental instability has any fitness consequences, we also investigated the relationship between developmental instability and individual condition for offspring under both treatments. We predicted that increased individual levels of asymmetry would correspond with lower body mass and body condition under both treatments.

\section{METHODS}

\section{Study site and populations}

The study was carried out between June and August of 1994 on eight experimental plots (between 6 and 28 ha each) located on four study sites within $32 \mathrm{~km}$ of one another in the Swan River Valley of western Montana. Each study site contained control (untreated) plots and plots where overstory vegetation was removed (VR plots) by the Plum Creek Timber Company. Overstory removal treatment included the removal of 250-500 trees/ha. After removal, trees were limbed at landings and debris was burned. Study sites were surrounded by large, contiguous forested stands. Timber harvesting occurred during spring of 1993 , one year prior to animal sampling. Trait measurements, asymmetry values, and age and sex ratios did not differ among study sites within treatments (all ANCOVA $F$ 's $<0.7$ ). Thus, we pooled data across study sites.

Studies in Eurasian shrews found that sexes differ in sizes and utilization of their home ranges (Stockley et al. 1994, 1996). While females remain within small home ranges throughout the year, males during breeding season commonly make linear movements up to $116 \mathrm{~m}$ (Stockley et al. 1994 and references therein). Similarly, $S$. cinereus has very limited natal and breeding dispersal (K. R. Foresman, unpublished data). However, to further minimize the effects of immigration, emigration, and edge effects, we limited our sampling to the core areas of our study plots. Concurrent studies which employed ear tagging all other small mammal species documented that no movement occurred between VR and control sites. Thus, it is very unlikely that we sampled any individuals from areas outside of our experimental setting. Shrews were trapped with pitfall traps or Sherman live traps during two weeks in June 1994. Sherman live traps were arrayed in $10 \times 10$ grids, spaced at $10-\mathrm{m}$ intervals, with one trap per station and baited with rolled oats. Trapping grids were run for four consecutive, 24-h periods and checked twice each day. In addition, three pitfall arrays containing four pitfalls each were placed across the core of each plot surrounding live trap grids. These unbaited traps were checked once per day. We aged captured shrews based on tooth wear (Dannelid 1994). For consistency, we restricted our analyses to immature 


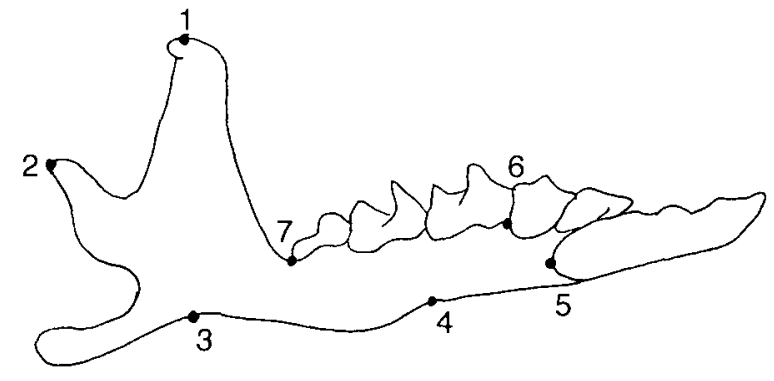

FIG. 1. Outline of a common shrew (Sorex cinereus) mandible showing eight landmark points used in this study: M1, 1-3; M2, 3-7; M3, 2-7; M4, 1-2; T1, 5-7; T2, 5-6; T3, 4-6; $\mathrm{T} 4,4-7$.

\section{Data collection and analyses}

After sacrifice, shrews were weighed to the nearest $0.01 \mathrm{~g}$ on an electronic balance, and sexed by dissection. The skulls were cleaned in a dermestid beetle colony. We then photographed images of left and right side of each mandible under $7.5 \times$ magnification using an Olympic SZH stereo photomicroscope and a video capture board. The resulting images were magnified $2 \times$ in the Mocha 1.2.10 Image Analysis software (Jandel Scientific, San Rafael, California, USA). We selected eight major landmark points, commonly used in shrew skull measurements (e.g., Dannelid 1994), along the lower mandible perimeter. Before designating distances for use in our analyses, we examined the repeatability of our measurements and only distances with $90 \%$ repeatability or higher were used. Repeatabilities for all traits were calculated from intraclass variance components of ANOVA from a subsample of 15 individuals remeasured multiple times over the period of one to five wk. We estimated whether individual variation in asymmetry differed from that estimated from measurement error by computing mean squares (MS) from a mixed-model ANOVA (SAS 1989; after Swaddle et al. 1994). We estimated repeatability by dividing the MS Individual $\times$ Side $\times$ Repeated measures by a sum of mS Individual $\times$ Side $\times$ Repeat and MS Individual $\times$ Repeat (Swaddle et al 1994). The asymmetry esti- mates derived with this method were significantly repeatable for both VR and control samples (15 individuals per location, all $F$ 's $\geq 10.8$, all $P^{\prime}$ 's $<0.001$ ).

We measured four characters in the posterior "muscle" area of the mandible (M1-M4; Fig. 1) and four characters in the anterior "teeth" area of the mandible (T1-T4; Fig. 1). Interlandmark distances were measured using Mocha Image Analyses Software. Because of the manifold magnification and accuracy of measurements made possible by this software, our measurement error (pixellation error) was $<0.3 \%$ of total variance in most mandible traits (by side) and $<10 \%$ of the average difference between sides for each trait. Both shrew mandible photography and mandible measurements were conducted without prior knowledge of habitat treatment affiliations. Thus, we assumed that the measurement error contributed equally to each sex and habitat treatment category.

Asymmetries in selected characters (M1-M4 and T1-T4) showed no scaling effects with character size (all Pearson $r$ 's $<0.10$ ). Plots of left minus right values and results of ANOVA (Tables 3,5 ) reveal only small directional asymmetry in measured traits. Means of left minus right differences for selected traits were not significantly different from zero, mostly showed no significant kurtosis or skewness, and did not deviate from normal distributions (Table 1). Therefore we concluded that eight selected distances could be used to reliably estimate fluctuating asymmetry (FA) in the lower mandible.

We calculated FA on both individual and population levels (Palmer and Strobeck 1986). Individual level estimates allowed us to examine the relationship between individual asymmetry levels and individual quality, and more importantly, the variation in this relationship among individuals. Estimates of asymmetry on the population level allowed us to compare population responses to changes in environmental conditions (i.e., vegetation removal). In addition, the variance-partitioning estimate of population-level asymmetry let us separate effects of directional and fluctuating asymmetry (Møller and Swaddle 1997). For the

TABLE 1. Skewness $(S)$, kurtosis $(K)$, and test for normality $(W)$ of the fluctuating asymmetry values for each of the eight mandibular measurements of Sorex cinereus in two habitat treatments after effects of sex were statistically controlled.

\begin{tabular}{cccccccc}
\hline & \multicolumn{3}{c}{ Control $(n=44)$} & & \multicolumn{3}{c}{ VR $(n=68)$} \\
\cline { 2 - 4 } \cline { 6 - 7 } Variable & $S$ & $K$ & $W$ & & $S$ & $K$ & $W$ \\
\hline M1 & 1.110 & 0.465 & 0.860 & & 0.961 & 0.613 & 0.911 \\
M2 & 0.999 & -0.447 & 0.814 & & 0.987 & 0.318 & 0.924 \\
M3 & 0.734 & -0.454 & 0.900 & & 0.708 & 0.387 & 0.873 \\
M4 & 1.161 & 0.533 & 0.835 & & 1.098 & 0.462 & 0.879 \\
T1 & 0.979 & 0.363 & 0.743 & & 0.787 & 0.233 & 0.863 \\
T2 & 1.165 & 0.999 & 0.776 & & 2.678 & 2.312 & 0.684 \\
T3 & 1.045 & 0.500 & 0.755 & & 0.818 & -0.607 & 0.862 \\
T4 & 1.127 & 0.159 & 0.815 & & 0.843 & 0.537 & 0.861 \\
\hline
\end{tabular}


TABLE 4. Fluctuating asymmetry values (mean, with $1 \mathrm{SE}$ in parentheses) for each of the eight mandibular measurements of Sorex cinereus in two habitat treatments after effects of sex were controlled.

\begin{tabular}{ccccc}
\hline \hline & \multicolumn{2}{c}{ Habitat } & & \\
\cline { 2 - 3 } Variable & Control & VR & $F$ & $P$ \\
\hline M1 & $0.008(0.002)$ & $0.015(0.001)$ & 8.15 & $0.005 \dagger$ \\
M2 & $0.010(0.003)$ & $0.017(0.002)$ & 4.11 & 0.046 \\
M3 & $0.011(0.002)$ & $0.015(0.002)$ & 1.39 & 0.241 \\
M4 & $0.009(0.003)$ & $0.017(0.002)$ & 5.13 & 0.026 \\
T1 & $0.006(0.002)$ & $0.014(0.001)$ & 8.75 & $0.004 \dagger$ \\
T2 & $0.018(0.008)$ & $0.036(0.006)$ & 3.30 & 0.073 \\
T3 & $0.016(0.005)$ & $0.037(0.004)$ & 10.43 & $0.001 \dagger$ \\
T4 & $0.009(0.004)$ & $0.034(0.003)$ & 20.67 & $<0.001 \dagger$ \\
\hline
\end{tabular}

Notes: $F$ values are for directional test of differences in asymmetry between control and vegetation-removal (VR) treatments. Sample sizes are as in Table 1.

$\dagger$ Significant difference between habitat treatments at $\alpha<0.10$ in sequential within-sex Bonferroni tests.

tributing $28.4 \%$ of total variance in characters in control population and $50.2 \%$ in VR population (Table 5). Population FA increases were proportionally the largest in T2 $(53 \%)$, T3 $(34 \%)$, and T4 $(39 \%)$ traits. Overall, population FA values increased by $16.3 \%$ per trait in

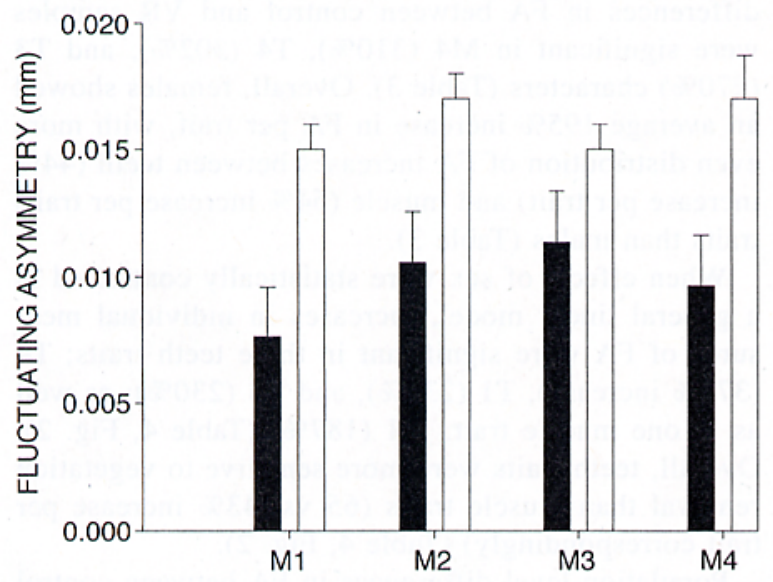

E્ટ
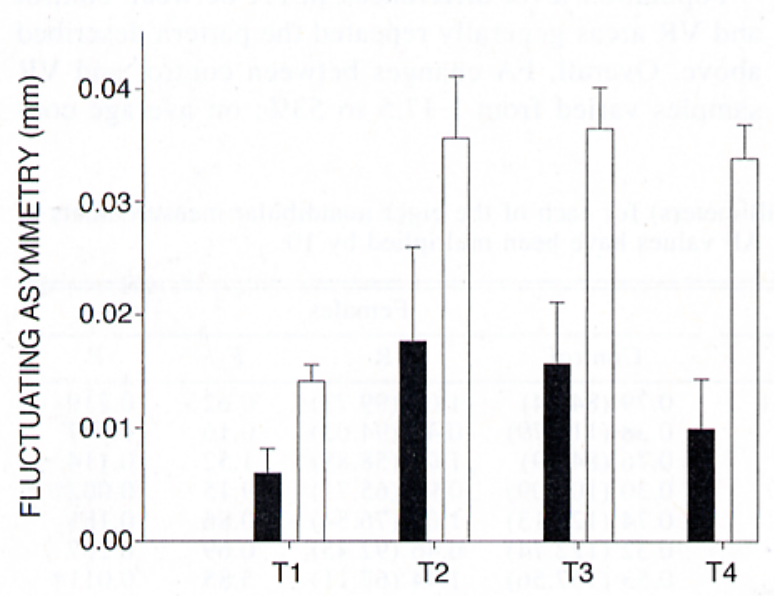

FIG. 2. Residual values of fluctuating asymmetry (mean + I SE; individual level, effects of sex removed) for eight mandibular measurements of Sorex cinereus from control (solid bars) and vegetation-removal (open bars) sites. muscle traits and by $27.2 \%$ per trait in teeth traits (Table 5, Fig. 3).

Shrews in the VR areas had significantly lower body mass and tended to be in lower individual condition (residuals of body mass vs. size regression; Jakob et al. 1996) compared to the control areas (Table 6). In both control and VR samples, shrews that had a higher degree of asymmetry were in lower individual condition (Table 6, Fig. 4). Furthermore, although not significant (ANCOVA, $F=0.76, P=0.38$ ), the slope of the FA index vs. individual condition regression was greater in the VR sample than in the control (Table 6, Fig. 4), suggesting that the consequences of asymmetry may be magnified under stressful conditions.

\section{Discussion}

Our results provide evidence for the strong effects of rapid environmental change on developmental stability in free-living populations of shrews. We documented a large increase in mandible asymmetry in shrews born under stressful conditions (Tables 3-5, Figs. 2 and 3). Despite pronounced differences in developmental stability of traits between the two treatments, there were no differences in the overall sizes of traits, and only small differences in individual conditions (Tables 1 and 6). This indicates that developmental stability in traits is more sensitive to changes in environmental conditions than the trait sizes themselves, and developmental stability may be a better indication of environmental quality than individual viability or population density estimates (Leary and Allendorf 1989).

High sensitivity of shrew developmental stability to the environmental conditions found in this study corroborates previous findings that variation in shrew behavior and morphology are excellent indicators of environmental change. Pankakoski et al. (1992) showed that developmental stability of Sorex araneus is strongly affected by heavy metal pollution. They suggested that reduced dispersal and short life span make shrews particularly sensitive to local environmental condi- 
TABLE 5. Estimates of variance (percentage of total variance in parentheses) components due to directional asymmetry (Side), individuals (Individual), and fluctuating asymmetry (Error) for each of the eight mandibular measurements. All estimates of variance (but not percentages) have been multiplied by $10^{5}$.

\begin{tabular}{|c|c|c|c|c|}
\hline Trait & Side & Individual & Error & Total \\
\hline \multicolumn{5}{|l|}{ Control } \\
\hline Ml & $0.0158(0.3)$ & $5.0322(90.8)$ & $0.6030 \quad(8.9)$ & 5.5404 \\
\hline M2 & $0.0236(0.4)$ & $4.5725(85.4)$ & $0.8622(14.3)$ & 5.3537 \\
\hline M3 & $0.0171(0.9)$ & $0.6494(34.7)$ & $1.2275(64.5)$ & 1.8723 \\
\hline M4 & $0.0336(0.3)$ & $9.1069(87.2)$ & $1.2656(12.4)$ & 10.204 \\
\hline $\mathrm{T} 1$ & $0.0000(0.0)$ & $0.5376(27: 1)$ & $1.4871(72.9)$ & 1.9807 \\
\hline $\mathrm{T} 2$ & $0.0000(0.0)$ & $16.175(81.5)$ & $4.0816(18.6)$ & 19.840 \\
\hline T3 & $0.3858(2.3)$ & $14.010(82.6)$ & $3.0553(15.1)$ & 16.965 \\
\hline T4 & $0.2367(3.0)$ & $5.8347(76.1)$ & $1.8122(20.7)$ & 7.6440 \\
\hline \multicolumn{3}{|c|}{ (Mean percentage } & $(28.4)$ & \\
\hline \multicolumn{5}{|c|}{ Vegetation removal } \\
\hline M1 & $0.0021 \quad(0.0)$ & $2.1718(57.0)$ & $1.6175(42.9)$ & 3.7710 \\
\hline M2 & $0.5742(10.2)$ & $3.5766(58.6)$ & $1.7939(31.9)$ & 5.6280 \\
\hline M3 & $0.0000 \quad(0.0)$ & $1.6976(50.8)$ & $1.6108(49.1)$ & 3.2799 \\
\hline M4 & $0.0000 \quad(0.0)$ & $3.1913(58.4)$ & $2.2462(41.7)$ & 5.3920 \\
\hline $\mathrm{T} 1$ & 0.0000 & $1.4134(44.7)$ & $1.7396(55.4)$ & 3.1410 \\
\hline $\mathrm{T} 2$ & 1.1809 & $5.7173(25.8)$ & $15.873(71.7)$ & 22.140 \\
\hline $\mathrm{T} 3$ & 2.0393 & $6.4937(44.0)$ & $7.2715(49.3)$ & 14.736 \\
\hline $\mathrm{T} 4$ & 1.5648 & $4.0643(33.9)$ & $7.1756(59.8)$ & 11.993 \\
\hline $\begin{array}{l}\text { (Mean percentage } \\
\text { of total variance) }\end{array}$ & $(3.3)$ & $(46.7)$ & $(50.2)$ & \\
\hline
\end{tabular}

tions. In addition, predatory insectivorous foraging makes shrews especially vulnerable to toxic pollutants in the environment (Pankakoski et al. 1992). Because most of the variation in developmental stability in skeletal characters arises during prenatal and early postnatal stages (e.g., Siegel and Doyle 1975b), physiological condition of pregnant females could be a proximate cause of variation in offspring asymmetry. Similarly, Zakharov et al. (1991) found that physiological conditions of females and developmental stability of their offspring strongly differed between geographic populations in $S$. araneus and were concordant with fluctuations in population density. Frequent territorial disputes, increased resource competition, and increases in predator numbers accounted for increased stress in shrews during peak population densities (Zakharov et al. 1991). Increased developmental instability during times when the population is under stress may be a byproduct of selection favoring increased phenotypic plasticity under novel environments introduced by stress (Cooper and Kaplan 1982, Bull 1987, Stearns and Kawecki 1994, Simmons and Johnson 1997, Badyaev and Ghalambor 1998). Under widely fluctuating environmental conditions, it is possible to envision how short life span and limited dispersal of shrews would favor maintenance of phenotypic plasticity for a number of traits (e.g., Schmalhausen 1949, Real 1980, Kieser 1987, Gavrilets and Hastings 1994, Stearns and Kawecki 1994). Examination of fitness consequences of developmental instability over a number of generations (Gillespie 1977) is needed to investigate this alternative.
Increased asymmetry was strongly associated with a short-term fitness in our study populations, corroborating results of several other studies (e.g., Pankakoski et al. 1992, Stockley et al. 1996). Strong correlation between fitness and asymmetry in the shrew mandible is not surprising given the close association of mandible traits with prey capturing (e.g., Carraway and Verts 1994), and nearly continuous foraging activity of shrews (Genoud 1988). The comparison of fitness consequences of asymmetry in control and VR treatments is significant because these treatments are concurrent with the natural array of environmental stresses experienced by our study populations. In both control and VR populations, asymmetrical shrews were in poorer conditions because they were significantly lighter for their size (Table 6; Fig. 4). However, while not statistically different, slope of FA vs. physiological condition regression was shallower in the control population (Fig. 4). This indicates that wider variation in asymmetry is tolerated under normal conditions, while similar ranges of variation under stressful conditions causes stronger decline in physiological condition (Fig. 4). Lower fitness of asymmetrical individuals is commonly documented (see Møller and Swaddle 1997 for review). It may arise directly through mating discrimination against asymmetrical individuals (e.g., Møller 1992), or higher vulnerability of such individuals to predators because of their reduced escape abilities (e.g., Swaddle et al. 1996, Møller and Nielsen 1997). Reduced fitness could also result from indirect effects of abnormal development, such as aberrations in behavioral phenotype of asymmetrical individuals that may exclude them 

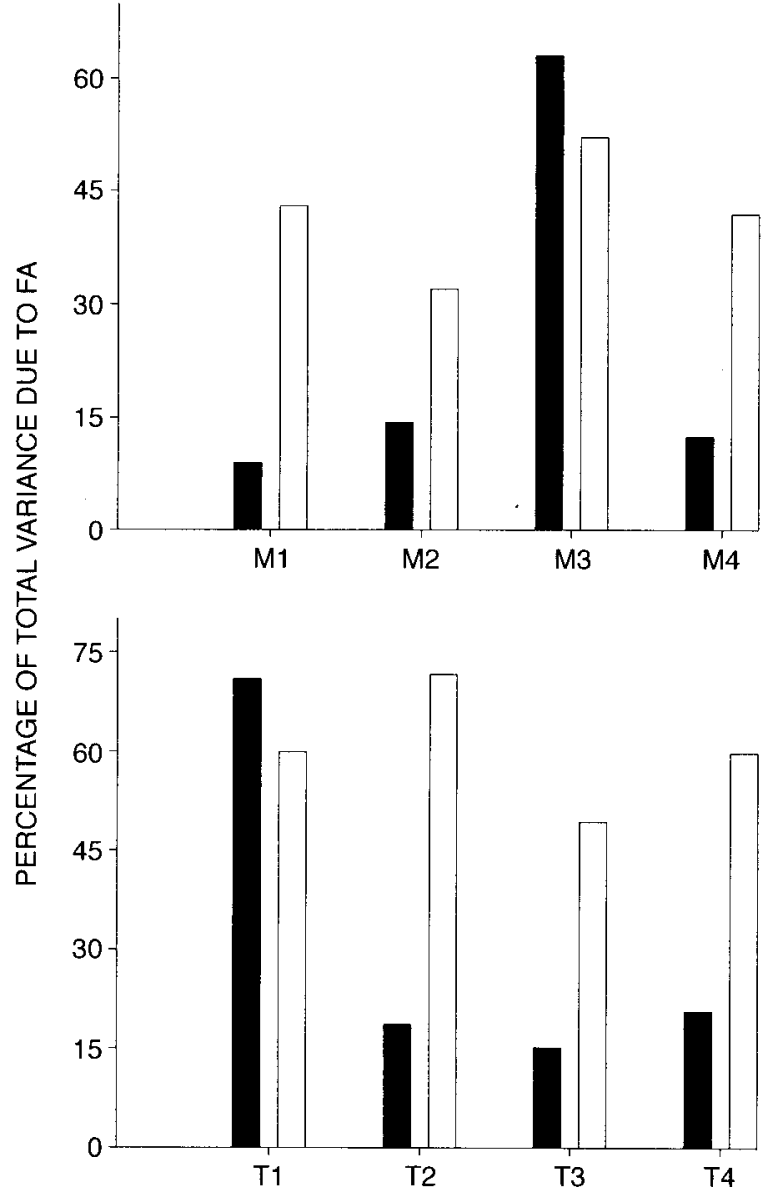

FIG. 3. Residual values of fluctuating asymmetry (population level, effects of sex removed) for eight mandibular measurements of Sorex cinereus from control (solid bars) and vegetation-removal (open bars) sites.

from the pool of potential mating partners, and make them more conspicuous to predators (e.g., Markow and Gottesman 1993). Finally, activation of individual stress-resistant mechanisms under stressful conditions may themselves lead to disruptive energetic balance and thus lower individual fitness (Orians and Solbrig 1977, Sibly and Calow 1989, Clarke and McKenzie 1992). The latter may also explain why a negative relationship between fitness and asymmetry is most frequently documented in wild populations under marginal ecological conditions (e.g., Parsons 1990).

Developmental stability was more sensitive to stressful conditions in males than in females (Table 3; see also Stockley et al. 1996). The reason for this is unclear. The mating system of $S$. cinereus is poorly known, but the closely related $S$. araneus is strongly polygynous and males intensively compete for access to females during an extremely short ( $2 \mathrm{~h}$ ) estrus period (Stockley et al. 1996). In S. araneus, the timing and intensity of body size growth appears to be more variable in males than in females, resulting in different mate-searching
TABLE 6. Mean (with $1 \mathrm{SD}$ in parentheses) of body mass (in grams), mandible size, and individual condition of Sorex cinereus from two habitat treatments after effects of sex were controlled.

\begin{tabular}{lcrcc}
\hline \hline \multicolumn{1}{c}{ Variable } & Control & VR & $F$ & $P$ \\
\hline Body mass & $3.35(0.83)$ & $2.97(0.62)$ & 4.93 & 0.01 \\
Mandible size $\dagger$ & $0.38(1.77)$ & $-0.15(1.90)$ & 1.55 & 0.12 \\
Condition $\neq$ & $0.16(1.65)$ & $-0.06(1.82)$ & 0.45 & 0.30 \\
$\begin{array}{l}\text { FA index vs. } \\
\quad \text { condition }\end{array}$ & & & & \\
$\left(b_{\text {sT }}\right)$ & -0.18 & -0.27 & 0.76 & 0.38 \\
\hline
\end{tabular}

Notes: $F$ values are for directional test of differences between control and vegetation-removal (VR) treatments. The last row reports standardized regression coefficients $\left(b_{\mathrm{ST}}\right)$ from a regression of FA index on condition.

$\uparrow$ First principal component from correlational matrix of 8 mandibular traits.

$\ddagger$ Residual of body mass vs. size regression.

strategies used by early- and late-maturing males (Stockley et al. 1994). Males that are larger at early stages of sexual maturation had large home ranges in areas with high female density, while smaller males had small home ranges and made long-distance movements to visit female ranges (Stockley et al. 1994). While $S$. cinereus is not sexually dimorphic in size (Table 2), there may be stronger selection on males to reach adult size and to establish breeding range. Thus, their faster, shorter, and more variable growth may be more sensitive to stress than growth of females.

Mandible traits strongly differed in their sensitivity to environmental conditions (Tables 3-5). The differential sensitivity of trait development to environmental change is assumed to be directly related to the intensity of stabilizing selection (e.g., Schmalhausen 1949, Mather 1953, Soulé and Cuzin-Roudy 1982, Kieser

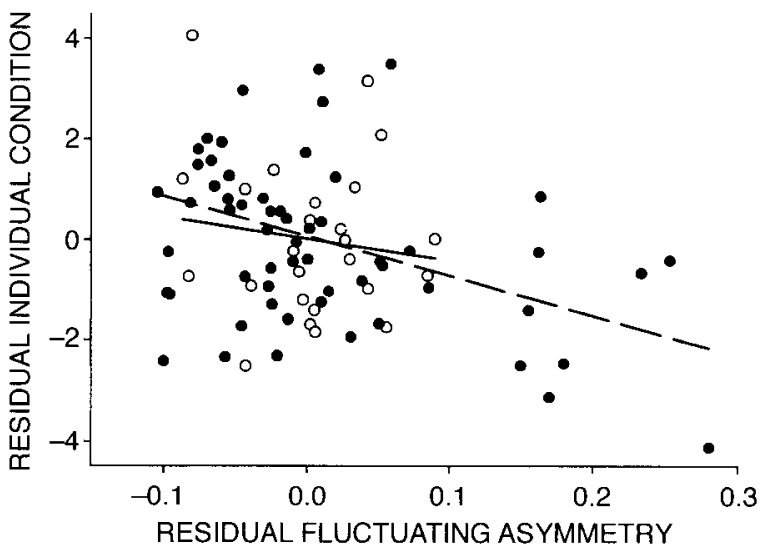

FIG. 4. The relationship between residual of sum of fluctuating asymmetry for each trait (FA index) and residual individual condition (effects of sex were removed) for mandibular measurements of Sorex cinereus from control (open circles, solid line) and vegetation-removal (solid circles, dashed line) plots. Overall linear regression (combining both habitat treatments): $b_{\mathrm{sT}}=-0.26, t=-2.36, P=0.002$. Slopes for the treatments are not significantly different from each other. 
1987). Traits of high functional importance, that are usually under stronger stabilizing selection, become highly canalized and are developmentally more buffered than less functionally important traits (Mather 1953, Kieser 1987, Gavrilets and Hastings 1994, Stearns and Kawecki 1994, Pomiankowski and Møller 1995). However, the developmental mechanisms that ultimately control differential developmental instability are poorly understood (e.g., Emlen et al. 1993, Moreno 1994 and references therein, Swaddle and Witter 1997). Our preliminary results indicate that mandible traits of shrews vary in degree of developmental and functional morphological integration (A. V. Badyaev and K. R. Foresman, unpublished manuscript). High morphological integration was closely associated with low stress-induced variation, and traits that show the smallest response to stress were also more closely related to individual fitness (A. V. Badyaev and K. R. Foresman, unpublished manuscript).

Stressful environmental conditions associated with vegetation removal could increase level of emigration from VR population (i.e., Badyaev et al. 1996). Alternatively, vegetation removal could facilitate immigration of lower quality individuals to VR sites from neighboring areas where they may be unable to compete for territories with higher quality individuals. Thus, if high-quality individuals left the poor-quality VR plots, and/or a higher proportion of low-quality individuals moved in before our sampling, increased asymmetry in the VR samples could reflect differential emigration or immigration in addition to response to stress. This explanation is unlikely, because of limited dispersal by shrews and restriction of our sampling to the central areas of experimental plots. In addition, animals in VR and control populations did not differ in individual condition, overall size of jaw, or in size of individual traits (Tables 2 and 6).

In sum, vegetation removal resulted in a strong decrease in developmental stability in free-living shrew populations. Increased asymmetry was associated with lower physiological condition in both populations, although the negative correlation between asymmetry and fitness were more pronounced under stressful conditions.

This study raised several questions. First, it is unclear whether high sensitivity of shrew developmental stability to environmental conditions indicates inability to undergo optimal development or selection favoring maintenance of phenotypic plasticity under fluctuating environments. Second, sex-biased sensitivities of development to stressful conditions remain to be explained. Finally, the mechanism behind differential sensitivity of various mandible traits to stress needs further examination.

\section{ACKNOWLEDGMENTS}

We thank Alison Banks, Peter Dunn, Cameron Ghalambor, John Fryxell, Douglas Emlen, Celeste Fiumara, Britt Heidinger, Jeffrey Karron, Wendy Parson, Karl Stanford, Dave Tall- mon, Josh Tewksbury, Linda Whittingham, and two anonymous reviewers for helpful discussions and comments on earlier versions of this paper. Rex McGraw and Greg Parkhurst helped in the collections of shrews.

\section{LITERATURE CITED}

Ames, L. J., J. D. Felley, and M. E. Smith. 1979. Amounts of asymmetry in centrarchid fish inhabiting heated and nonheated reservoirs. Transactions of the American Fisheries Society 108:489-495.

Badyaev, A. V. 1998. Environmental stress and developmental stability in dentition of Yellowstone grizzly bears. Behavioral Ecology 9:339-344.

Badyaev, A. V., W. J. Etges, J. D. Faust, and T. E. Martin. 1998. Fitness correlates of spur length and spur asymmetry in male wild turkeys (Meleagris gallopavo L.). Journal of Animal Ecology 67:845-852.

Badyaev A. V., W. J. Etges, and T. E. Martin. 1996. Ecological and behavioral correlates of variation in seasonal home ranges. Journal of Wildlife Management 60:154-164.

Badyaev, A. V., and C. K. Ghalambor. 1998. Does a tradeoff exist between sexual ornamentation and ecological plasticity? Sexual dichromatism and occupied elevational range in finches. Oikos 82:319-325.

Bailit, H. L., P. L. Workman, J. D. Niswander, and C. J. Maclean. 1970. Dental asymmetry as an indicator of genetic and environmental conditions in human populations. Human Biology 42:626-638.

Bradshaw, A. D. 1965. Evolutionary significance of phenotypic plasticity in plants. Advances in Genetics 13:115163.

Bull, J. J. 1987. Evolution of phenotypic variance. Evolution 41:303-315.

Carraway, L. N., and B. J. Verts. 1994. Relationship of mandibular morphology to relative bite force in some Sorex from western North America. Pages 201-210 in J. F. Merritt, G. L. Kirkland, Jr., and R. K. Rose, editors. Advances in the biology of shrews. Carnegie Museum of Natural History Special Publication Number 18, Pittsburgh, Pennsylvania, USA.

Chen, J., F. Franklin, and T. A. Spies. 1993. Contrasting microclimates among clearcut, edge, and interior of oldgrowth Douglas-fir forest. Agricultural and Forest Meteorology 63:219-237.

Churchfield, S. 1982. Food availability and the diet of the common shrew Sorex araneus in Britain. Journal of Animal Ecology 51:15-28.

Clarke, G. M., and J. A. McKenzie. 1992. Coadaptation, developmental stability, and fitness of insecticide resistance genotypes in the Australian sheep blowfly, Lucilia cuprina: a review. Acta Zoologica Fennica 191:107-110.

Cooper, W. S., and R. H. Kaplan. 1982. Adaptive "coinflipping": a decision-theoretic examination of natural selection for random individual variation. Journal of Theoretical Biology 94:135-151.

Dannelid, E. 1994. Comparison of pigment and other dental characters of eastern Palearctic Sorex (Mammalia: Soricidae). Pages 217-231 in J. F. Merritt, G. L. Kirkland, Jr., and R. K. Rose, editors. Advances in the biology of shrews. Carnegie Museum of Natural History Special Publication Number 18.

Emlen, J. M., C. D. Freeman, and J. D. Graham. 1993. Nonlinear growth dynamics and the origin of fluctuating asymmetry. Genetica 89:77-96.

Foresman, K. R. 1994. Comparative embryonic development of the Soricidae. Pages 241-258 in J. F. Merritt, G. L. Kirkland, Jr., and R. K. Rose, editors. Advances in the biology of shrews. Carnegie Museum of Natural History Special Publication Number 18.

Foresman, K. R., and R. D. Long. 1998. The reproductive cycle of the vagrant shrew (Sorex vagrans) and the common 
shrew (Sorex cinereus) in Montana. American Midland Naturalist 139: 108-113.

Gavrilets, S., and A. Hastings. 1994. A quantitative-genetic model for selection on developmental noise. Evolution 48: $1478-1486$.

Geier, A. R., and L. B. Best. 1980. Habitat selection by small mammals in riparian communities: evaluating effects of habitat alterations. Journal of Wildlife Management 44: 1622.

Genoud, M. 1988. Energetic strategies of shrews: Ecological constraints and evolutionary implications. Mammal Review 18: 173-193.

Gillespie, J. H. 1977. Natural selection for variances in offspring numbers: a new evolutionary principle. American Naturalist 111:1010-1014.

Graham, J. H., D. C. Freeman, and J. M. Emlen. 1993. Antisymmetry, directional asymmetry, and dynamic morphogenesis. Genetica 89:121-137.

Harris, E. F., and M. T. Nweeia. 1980. Dental asymmetry as a measure of environmental stress in the Tocuna Indians of Columbia. American Journal of Physical Anthropology 53: $133-142$.

Hoffmann, A. A., and P. A. Parsons. 1991. Evolutionary genetics and environmental stress. Oxford University Press, Oxford, UK.

Holloway, G. J., H. J. Crocker, and A. Callaghan. 1997. The effects of novel and stressful environments on trait distribution. Functional Ecology 11:579-584.

Jagoe, C. H., and T. A. Haines. 1985. Fluctuating asymmetry in fishes inhabiting acidified and unacidified lakes. Canadian Journal of Zoology 63:130-138.

Jakob, E. M., S. D. Marshall, and G. W. Uetz. 1996. Estimating fitness: a comparison of body condition indices. Oikos 77:61-67.

Kieser, J. A. 1987. Epigenetic canalization and phenotypic change: a minimax model. Medical Hypotheses 22:105110 .

Kieser, J. A. 1993. Evolution, developmental instability and the theory of acquisition. Genetica 89:219-225.

Leary, R. F., and G. W. Allendorf. 1989. Fluctuating asymmetry as an indicator of stress: implications for conservation biology. Trends in Ecology and Evolution 4:214217.

Manning, J. T., and A. T. Chamberlain. 1994. Fluctuating asymmetry in gorilla canines: a sensitive indicator of environmental stress. Proceedings of the Royal Society London B 255: 189-193.

Markow, T. A., and I. I. Gottesman. 1993. Behavioral phenodeviance: a Lerneresque conjecture. Genetica 89:297-305. Mather, K. 1953. Genetical control of stability in development. Heredity 7:297-336.

McShea, W. J., and D. M. Madison. 1989. Measurement of reproductive traits in a field population of meadow voles. Journal of Mammalogy 70:132-141.

Møller, A. P. 1992. Female swallow show preference for symmetrical male sexual ornaments. Nature 357:238-240. Møller, A. P. 1993. Morphology and sexual selection in the barn swallow Hirundo rustica in Chernobyl Ukraine. Proceedings of the Royal Society London B 252:51-57.

Møller, A. P., and J. T. Nielsen. 1997. Differential predation cost of a secondary sexual character: sparrowhawk predation on barn swallow. Animal Behaviour 54:1545-1551. Møller, A. P., and A. Pomiankowski. 1993. Fluctuating asymmetry and sexual selection. Genetica 89:267-279.

Møller, A. P., and J. P. Swaddle. 1997. Asymmetry, developmental stability, and evolution. Oxford University Press, Oxford, UK.

Moreno, G. 1994. Genetic architecture, genetic behavior, and character evolution. Annual Reviews of Ecology and Systematics 25:31-44.
Orians, G. H., and O. T. Solbrig. 1977. A cost-income model of leaves and roots with special reference to arid and semiarid areas. American Naturalist 111:677-690.

Palmer, A. R., and C. Strobeck, 1986. Fluctuating asymmetry: measurements analysis patterns. Annual Reviews in Ecology and Systematics 17:391-421.

Pankakoski, E., I. Koivisto, and H. Hyvrinen. 1992. Reduced developmental stability as an indicator of heavy metal pollution in the common shrew Sorex araneus. Acta Zoologica Fennica 191:137-144.

Parsons, P. A. 1990. Fluctuating asymmetry: an epigenetic measure of stress. Biological Reviews 65:131-145.

Parsons, P. A. 1993. Developmental stability and the limits of adaptation: interactions with stress. Genetica 89:245253.

Picton, H. D., D. Palmisciano, and G. Nelson. 1992. Fluctuating asymmetry and testing isolation of Montana grizzly bear populations. International Conference of Bear Res Management 8:421-424.

Pomiankowski, A., and A. P. Møller. 1995. A resolution of the lek paradox. Proceedings of the Royal Society London B 260:21-29.

Real, L. A. 1980. Fitness, uncertainty, and the role of diversification in evolution and behavior. American Naturalist 115:623-638.

Rasmuson, M. 1960. Frequency of morphological deviations as a criterion of developmental stability. Hereditas 46:51536.

Reeve, E. C. R. 1960. Some genetic tests on asymmetry of sternopleural chaeta number in Drosophila. Genetic Research 1:151-172.

SAS Institute, 1989. SAS/STAT user's guide, version 6. Cary, North Carolina, USA.

Schmalhausen, I. I. 1949. Factors of evolution. Blakiston, Philadelphia, Pennsylvania, USA.

Sciulli, P. W., W. J. Doyle, C. Kelley, P. Siegel, and M. I. Siegel. 1979. The interaction of stressors in the induction of increased levels of fluctuating asymmetry in the laboratory rat. American Journal of Physical Anthropology 50: 279-284.

Selyé, H. 1956. The stress of life. McGraw-Hill, New York, New York, USA.

Shandorff, S. 1997. Developmental stability and skull lesions in the harbour seal (Phoca vitulina) in the 19th and 20th centuries. Ann Zoologica Fennici 34:151-166.

Sibly, R. M., and Calow, P. 1989. A life-cycle theory of responses to stress. Biological Journal of Linnean Society 37: $101-116$.

Siegel, M. I., and W. J. Doyle. 1975a. Stress and fluctuating limb asymmetry in various species of rodents. Growth 39: $363-369$.

Siegel, M. I., and W. J. Doyle. 1975b. The differential effects of prenatal and postnatal audiogenic stress on fluctuating dental asymmetry. Journal of Experimental Zoology 191 : 211-214.

Siegel, M. I., M. P. Mooney, and A. B. Taylor. 1992. Dental and skeletal reduction as a consequence of environmental stress. Acta Zoologica Fennica 191:145-149.

Siegel, M. I., and H. H. Smookler. 1973. Fluctuating dental asymmetry and audiogenic stress. Growth 37:35-39.

Simmons, A. M., and M. O. Johnston. 1997. Developmental stability as a bet-hedging strategy. Oikos 80:401-406.

Soulé, M. E., and J. Cuzin-Roudy. 1982. Allometric variation. 2. Development instability of extreme phenotypes. American Naturalist 120:765-786.

Stearns, S. C., and T. J. Kawccki. 1994. Fitness sensitivity and the canalization of life-history traits. Evolution 48 : $1438-1450$.

Stockley, P., J. B. Searle, D. W. Macdonald, and C. S. Jones 1994. Alternative reproductive tactics in male common 
shrews: relationships between mate-searching behaviour, sperm production, and reproductive success as revealed by DNA fingerprinting. Behavioral Ecology and Sociobiology 34:71-78.

Stockley, P., J. B. Searle, D. W. Macdonald, and C. S. Jones. 1996. Correlates of reproductive success within alternative mating tactics of the common shrew. Behavioral Ecology 7:334-340.

Swaddle, J. P., and M. S. Witter. 1997. On the ontogeny of developmental stability in a stabilized trait. Proceedings of the Royal Society London B 264:329-334.

Swaddle, J. P., M. S. Witter. I. C. Cuthill. 1994. The analysis of fluctuating asymmetry. Animal Behaviour 48:986-989. Swaddle, J. P.. M. S. Witter, I. C. Cuthill, A. Budden, and P. McCowen. 1996. Plumage condition affects flight performance in Common Starlings: implications for developmental homeostasis, abrasion and molt. Journal of Avian Biology 27:3-11.

Valentine, D. W., and M. Soul. 1973. Effect of p.p' DDT on developmental stability of pectoral fin rays in the grunion, Leuresthes tenuis. Fisheries Bulletin 71:921-926.

Van Valen, L. 1962. A study of fluctuating asymmetry. Evolution 16:125-142.

Via, S. 1994. The evolution of phenotypic plasticity: what do we really know? Pages 35-57 in L. A. Real editor. Ecological genetics. Princeton University Press, Princeton, New Jersey, USA.

Wayne, R. K., W. S. Modi, and S. J. O'Brien. 1986. Morphological variability and asymmetry in the cheetah (Acinonix jubatus) a genetically uniform species. Evolution 40: $78-85$.

Zakharov, V. M., E. Pankakoski, B. I. Sheftel, A. Prltonen, and I. Hanski 1991. Developmental stability and population dynamics in the common shrew, Sorex araneus. American Naturalist 138:797-810.

Zakharov, V. M, and A. V. Yablokov. 1989. Skull asymmetry in the Baltic grey seal: effects of environmental pollution. Ambio 19:266-269. 